\title{
上下動中の ACV バッグスカートの変形特性について*1 Deformation of the Bag Skirt of ACV in Heave Motion
}

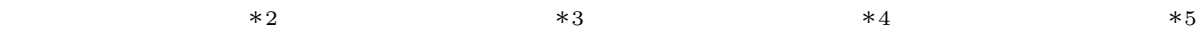 \\ Hiromitsu Senba, Hideo Matsuo, Hiroyuki Ishikawa, Shintarou Yoshimoto, \\ 廣 江 哲 幸 $* 6$ 藤 原 和 人 $^{* 6}$ \\ Tetsuyuki Hiroe and Kazuhito Fujiwara
}

Key Words : ACV, GEM, Aircushion, Bag Skirt

\begin{abstract}
A method to predict the change of the cushion pressure and the bag skirt configuration of ACV in heave is proposed. It is a quasistatic analysis based on the analysis of the skirt configuration in static operation that was proposed by the present authors. The cushion pressure depends on the velocity of motion as well as the hoverheight. It is higher in the downward motion than in the upward motion with the same hoverheight. As the model approaches the ground surface, the bag skirt is pushed outwards and also upwards but the hoverheight still decreases. This produces the increase of the cushion pressure that also flattened the configuration of the bag. The outward displacement of the bag produces the additional increase of the cushion base area and increases the restoring force. The stability is then increased.
\end{abstract}

\section{1. ま え がき}

$\mathrm{ACV}$ に装着されるバッグスカートが兴の安定性 , 凌波 性を著しく改良し実用化に対して大きな寄与をしたことは いまさら述べるまでもないことであるが，スカートの運転 中における形状推定法, とくに動摇中における形状変化に ついての研究は少ない．筆者らは前報 ${ }^{1 \sim 3)}$ において静止状 態にある ACV のスカート形状の解析法を提案し, スカー 卜形状が, モデルの幾何学特性, 空気の供給状況等によっ てどう変化するかに関して理論および実験の両面での研究 を行いほぼ満足すべき結果を得ている .

本報では前報の方法を拡張してモデルが上下動を行って いるときのスカート形状の変化を静止状態でのスカートの 変形特性を用いて準静的に調べた. 弚の結果, 上下動中の クッション圧はモデルの上下位置のみならず, 上下方向の 変位速度にも依存すること, モデルが地面に近づくにつれ てスカートは扁平化し, 上方に押し上げられるがスカート 下端と地面との間隙距離 (浮揚高) は反対に減少すること， スカートを装着することによって上下方向復元性が増加す ること等の興味深い結果が得られた .

\section{2. 理 論 解 析}

2.1 基礎式 第 1 図は動摇中のプリナムチャンバー型

\footnotetext{
*1 (C) 2004 日本航空宇宙学会

平成 15 年 8 月 29 日原稿受理

*2 熊本大学大学院自然科学研究科

$* 3$ 熊本大学名誉教授

*4 日産自動車 (株)

*5 (株) 椿本チエイン

$* 6$ 熊本大学工学部
}

$\mathrm{ACV}$ の模式図を示している. 理想的な場合として長方形 モデルで炎の両端が閉鎖された奥行き $(1 / 2) C$ のモデルを 考える.図において， $B$ はスカート下端で測ったクッショ ン幅, $\dot{H}$ はモデルの上下動速度である．

モデルの各断面内流れには 2 次元性が成り立つものと仮 定する.図において， $P_{\mathrm{c}}$ はクッション圧力， $P_{\mathrm{b}}$ はスカート のバッグ内圧力である .クッションへの空気供給系統とバッ グへの空気供給系統の相互関係によって， $P_{\mathrm{c}}$ と $P_{\mathrm{b}}$ との関 係は異なる．実際には空気供給方式は多岐にわたり，一般 的に論ずることは困難である．また，両者の相互干渉を考 慮することは光れ自体一つの課題であり, 別途考える必要 がある．ここでは，この不確定要素を除去するためにクッ ション空気とバッグ内の空気とは独立に供給されているも のとする .すなわち, クッション部には送風機によって流 量 $Q_{\mathrm{f}}$ が供給されており, バッグ内は別途供給される空気 によって一定圧力に保たれるものとする . 第 2 図にスカー 卜の幾何学的特性量を図示する. 図に示すように，スカー 卜の内側取り付け位置を原点とし，水平方向に $X$ 軸，鉛 直方向に $Y$ 軸をとる . 図で $L_{\mathrm{h}}, L_{\mathrm{v}}$ はスカートの外側およ び内側取り付け位置の相対距離, $H$ はスカート内側取り付 け位置から地面までの鉛直方向距離で時刻 $t$ の関数である。 また， $B_{0}$ はスカート内側取り付け位置で測ったクッション 幅， $B$ は第 1 図に示した通り，スカート膨張時のスカート 下端で測ったクッション幅である . 他の記号については以 下必要に応じて説明する.

クッション圧力 $P_{\mathrm{c}}$ は

$$
P_{\mathrm{c}}=P_{\mathrm{f}}-\zeta \frac{\rho}{2}\left(\frac{Q_{\mathrm{f}}}{S_{\mathrm{f}}}\right)^{2}
$$




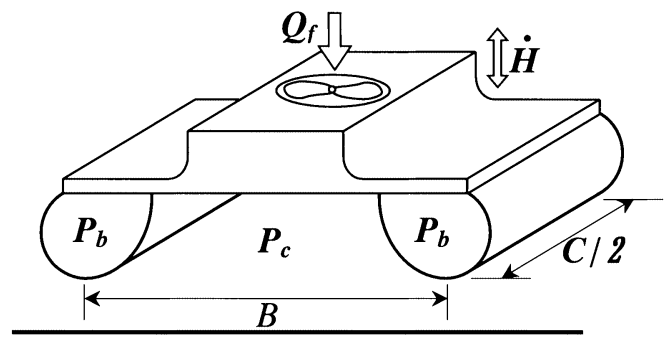

第1図 プリナムチャンバー型 $\mathrm{ACV}$ 模式図

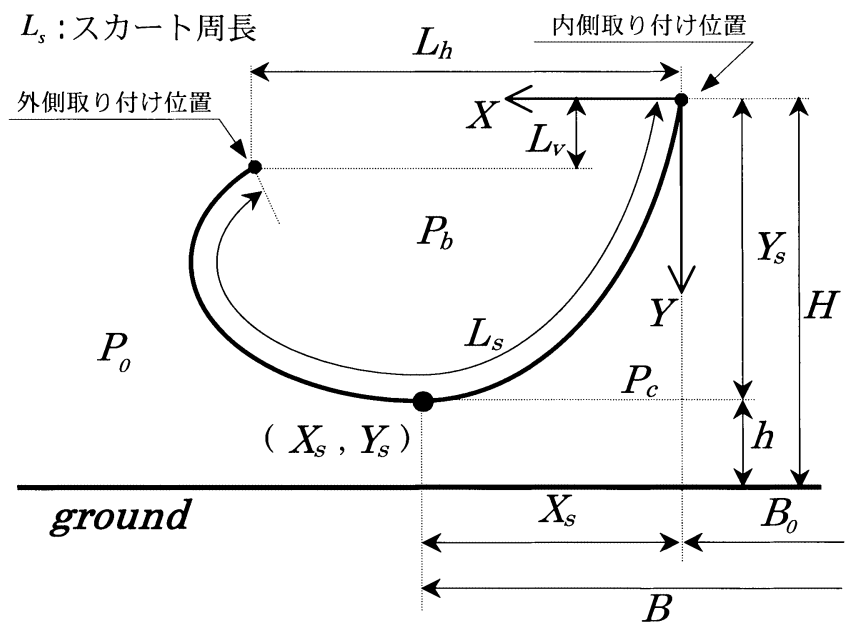

第 2 図 スカートの幾何学的特性量

ただし， $P_{\mathrm{f}}$ は送風機吐出全圧， $\zeta$ は管路損失係数， $\rho$ は空 気密度, $Q_{\mathrm{f}}$ は送風機吐出流量, $S_{\mathrm{f}}$ は送風機吐出口の断面 積である。

単位時間あたりのクッション内空気の増加量 $Q_{\mathrm{c}}$ は準静 的に

$$
Q_{\mathrm{c}}=Q_{\mathrm{f}}-C C_{\mathrm{d}} h \sqrt{\frac{2 P_{\mathrm{c}}}{\rho}}
$$

と表される.ここで $h$ はスカート下端と地面との間隙距離 (浮揚高)， $C_{\mathrm{d}}$ は流量係数を示している.

一方, クッション体積の時間的変化率は $\mathrm{d}(B C H) / \mathrm{d} t$ と 表されるので，

$$
Q_{\mathrm{c}}=\frac{\mathrm{d}(B C H)}{\mathrm{d} t}
$$

とも表される .この式を $(2)$ 式に代入すると，

$$
\frac{\mathrm{d}(B C H)}{\mathrm{d} t}=Q_{\mathrm{f}}-C C_{\mathrm{d}} h \sqrt{\frac{2 P_{\mathrm{c}}}{\rho}}
$$

また，管路損失を $\zeta \fallingdotseq 0$ とすると (1) 式は

$$
P_{\mathrm{c}}=P_{\mathrm{f}}
$$

となる．

送風機は回転数一定で作動しているものと仮定する. 送 風機特性は，

$$
P_{\mathrm{f}}=P_{\mathrm{f}}\left(Q_{\mathrm{f}}\right)
$$

と表される

次に , バッグスカートの形状について考える . 各瞬間に おけるクッション圧力の変化に応じたクッション幅の時間 的変動を考慮する必要がある. 第 2 図よりクッション幅 $B$ は,

$$
B=B_{0}+2 X_{\mathrm{s}}
$$

ここで $X_{\mathrm{s}}$ はスカート内側取り付け位置とスカート最下点 との水平方向距離で圧力比 $P_{\mathrm{c}} / P_{\mathrm{b}}$ によって決定される值で ある · すなわち ,

$$
X_{\mathrm{s}}=X_{\mathrm{s}}\left(P_{\mathrm{c}} / P_{\mathrm{b}}\right)
$$

また第 2 図より，スカート下端と地面との間隙距離 $h$ に関 して

$$
h=H-Y_{\mathrm{s}}
$$

$Y_{\mathrm{s}}$ はスカート内側取り付け位置とスカート最下点との鉛直 方向距離を表す． $Y_{\mathrm{s}}$ は圧力比 $P_{\mathrm{c}} / P_{\mathrm{b}}$ によって決定される 值である．すなわち，

$$
Y_{\mathrm{s}}=Y_{\mathrm{s}}\left(P_{\mathrm{c}} / P_{\mathrm{b}}\right)
$$

以上をまとめて解析に必要な式を列挙すると下の通りで ある

$$
\begin{aligned}
& \mathrm{d}(B C H) / \mathrm{d} t=Q_{\mathrm{f}}-C C_{\mathrm{d}} h \sqrt{2 P_{\mathrm{c}} / \rho} \\
& P_{\mathrm{c}}=P_{\mathrm{f}} \\
& P_{\mathrm{f}}=P_{\mathrm{f}}\left(Q_{\mathrm{f}}\right) \\
& B=B_{0}+2 X_{\mathrm{s}} \\
& X_{\mathrm{s}}=X_{\mathrm{s}}\left(P_{\mathrm{c}} / P_{\mathrm{b}}\right) \\
& h=H-Y_{\mathrm{s}} \\
& Y_{\mathrm{s}}=Y_{\mathrm{s}}\left(P_{\mathrm{c}} / P_{\mathrm{b}}\right)
\end{aligned}
$$

上の 7 個の基礎式に含まれる未知関数は $Q_{\mathrm{f}}, P_{\mathrm{f}}, P_{\mathrm{c}}$ ， $B, X_{\mathrm{s}}, Y_{\mathrm{s}}, h$ の 7 個であり上の 7 個の式が解析に必要な 方程式系を与えている.ここで， $X_{\mathrm{s}}=X_{\mathrm{s}}\left(P_{\mathrm{c}} / P_{\mathrm{b}}\right), Y_{\mathrm{s}}=$ $Y_{\mathrm{s}}\left(P_{\mathrm{c}} / P_{\mathrm{b}}\right)$ のつの関数は既知として与えられているが， 実はこの関数は上下動の各瞬間における圧力に対応するス カートの静的形状を求めて得られるものである . すなわち， 各瞬間において前報 2 , 3) の方法を適用してスカート形状を 求め, 谷の結果から $X_{\mathrm{s}}, Y_{\mathrm{s}}$ を求めねばならない.これは複 杂隹な繰り返し計算を必要とし, 計算時間の増大を招く.こ れを避けるために，ここでは前もって前報の方法2,3)によっ て $, X_{\mathrm{s}}, Y_{\mathrm{s}}$ と $P_{\mathrm{c}} / P_{\mathrm{b}}$ との関係を求め $P_{\mathrm{c}} / P_{\mathrm{b}}$ の多項式で近 似する . これによって計算の手順が著しく簡素化される .

\section{2 基礎式の無次元表示 (4) 式の左辺において}

$$
\frac{\mathrm{d}(B H)}{\mathrm{d} t}=\frac{\mathrm{d} B}{\mathrm{~d} t} H+B \frac{\mathrm{d} H}{\mathrm{~d} t}
$$


また

$$
B=B_{0}+2 X_{\mathrm{s}}
$$

したがって

$$
\frac{\mathrm{d} B}{\mathrm{~d} t}=2 \frac{\mathrm{d} X_{\mathrm{s}}}{\mathrm{d} t}=2 \frac{\mathrm{d} X_{\mathrm{s}}}{\mathrm{d}\left(P_{\mathrm{c}} / P_{\mathrm{b}}\right)} \cdot \frac{\mathrm{d}\left(P_{\mathrm{c}} / P_{\mathrm{b}}\right)}{\mathrm{d} t}
$$

(7)，(12) 式を (11) 式に代入すると

$$
\begin{aligned}
\frac{\mathrm{d}(B H)}{\mathrm{d} t}= & 2 \frac{\mathrm{d} X_{\mathrm{s}}}{\mathrm{d}\left(P_{\mathrm{c}} / P_{\mathrm{b}}\right)} \cdot \frac{\mathrm{d}\left(P_{\mathrm{c}} / P_{\mathrm{b}}\right)}{\mathrm{d} t} H \\
& +\left(B_{0}+2 X_{\mathrm{s}}\right) \frac{\mathrm{d} H}{\mathrm{~d} t}
\end{aligned}
$$

ここで, 送風機の流量係数 $\xi$, 圧力係数 $\psi$ を定義する.

$$
\begin{aligned}
\xi & =4 Q_{\mathrm{f}} /\left(\pi^{2} D^{3} n_{\mathrm{f}}\right) \\
\psi & =2 P_{\mathrm{f}} /\left(\rho \pi^{2} D^{2} n_{\mathrm{f}}{ }^{2}\right)
\end{aligned}
$$

ここで, $D$ は送風機の代表寸法 (直径)，また $\psi$ は $\xi の$ 関 数である.

$$
\begin{aligned}
& P_{\mathrm{c}}=P_{\mathrm{f}} \text { であるから }(15) \text { 式より } \\
& \qquad \frac{\mathrm{d}\left(P_{\mathrm{c}} / P_{\mathrm{b}}\right)}{\mathrm{d} t}=\frac{\rho \pi^{2} D^{2} n_{\mathrm{f}}{ }^{2}}{2 P_{\mathrm{b}}} \psi^{\prime}(\xi) \dot{\xi}
\end{aligned}
$$

ただし，

$$
\psi^{\prime}(\xi)=\frac{\mathrm{d} \psi}{\mathrm{d} \xi}
$$

を表す．

(16) 式を (13) 式に代入すると

$$
\begin{aligned}
\frac{\mathrm{d}(B H)}{\mathrm{d} t}= & \frac{\rho \pi^{2} D^{2} n_{\mathrm{f}}{ }^{2}}{P_{\mathrm{b}}} \cdot \frac{\mathrm{d} X_{\mathrm{s}}}{\mathrm{d}\left(P_{\mathrm{c}} / P_{\mathrm{b}}\right)} \psi^{\prime}(\xi) \dot{\xi} H \\
& +\left(B_{0}+2 X_{\mathrm{s}}\right) \frac{\mathrm{d} H}{\mathrm{~d} t}
\end{aligned}
$$

(4) 式の右辺に $(9),(14),(15)$ 式を代入し, $P_{\mathrm{c}}=P_{\mathrm{f}}$ の関 係を用いると

$$
\begin{aligned}
Q_{\mathrm{f}} & -C C_{\mathrm{d}} h \sqrt{\frac{2 P_{\mathrm{c}}}{\rho}} \\
& =\frac{\pi^{2} D^{3} n_{\mathrm{f}} \xi}{4}-C C_{\mathrm{d}}\left(H-Y_{\mathrm{s}}\right) \pi D n_{\mathrm{f}} \sqrt{\psi(\xi)}
\end{aligned}
$$

モデルの上下動が周期 $T$ の周期運動であるとし，無次元 時刻

$$
\tau=\frac{t}{T}
$$

を定義する．また，

$$
\psi_{\mathrm{b}}=\frac{2 P_{\mathrm{b}}}{\rho \pi^{2} D^{2} n_{\mathrm{f}}^{2}}
$$

とおく .

(18)，(19) 式を（4) 式に代入し，(20)，(21) 式を用いて
変形すると

$$
\begin{aligned}
& 2 \frac{\mathrm{d}\left(X_{\mathrm{s}} / L_{\mathrm{h}}\right)}{\mathrm{d}\left(P_{\mathrm{c}} / P_{\mathrm{b}}\right)} \frac{H}{L_{\mathrm{h}}} \frac{\psi^{\prime}(\xi)}{\psi_{\mathrm{b}}} \frac{\mathrm{d} \xi}{\mathrm{d} \tau}+\left(\frac{B_{0}}{L_{\mathrm{h}}}+2 \frac{X_{\mathrm{s}}}{L_{\mathrm{h}}}\right) \frac{\mathrm{d}}{\mathrm{d} \tau}\left(\frac{H}{L_{\mathrm{h}}}\right) \\
& =\frac{\pi^{2}}{4} \frac{L_{\mathrm{h}}}{C}\left(\frac{D}{L_{\mathrm{h}}}\right)^{3} T n_{\mathrm{f}} \xi \\
& \quad-\pi C_{\mathrm{d}}\left(\frac{H}{L_{\mathrm{h}}}-\frac{Y_{\mathrm{s}}}{L_{\mathrm{h}}}\right) \frac{D}{L_{\mathrm{h}}} T n_{\mathrm{f}} \sqrt{\psi(\xi)}
\end{aligned}
$$

また，(5)，(15)，(21) 式より

$$
\frac{P_{\mathrm{c}}}{P_{\mathrm{b}}}=\frac{\psi(\xi)}{\psi_{\mathrm{b}}}
$$

ただし， $X_{\mathrm{s}} / L_{\mathrm{h}}, Y_{\mathrm{s}} / L_{\mathrm{h}}$ は $P_{\mathrm{c}} / P_{\mathrm{b}}$ の多項式で表される .

結局，(22), (23) 式は未知関数 $\xi(\tau)$ と $P_{\mathrm{c}} / P_{\mathrm{b}}$ に関する 連立微分方程式となる。

\section{3. 解析}

3.1 解析条件 上下動を周期 $T$ の単振動と考える.

$$
H=H_{0}+\Delta H \cdot \sin \left(\frac{2 \pi}{T} t\right)
$$

計算において想定した各種無次元係数は下の通りである .

$$
\begin{aligned}
\frac{H_{0}}{L_{\mathrm{h}}} & =0.867 \\
\frac{\Delta H}{L_{\mathrm{h}}} & =0.033,0.067,0.100,0.133 \\
& \left(\frac{\Delta H}{H_{0}}=0.038,0.077,0.115,0.154\right) \\
\frac{D}{L_{\mathrm{h}}} & =1.97, \quad \frac{C}{L_{\mathrm{h}}}=5.33, \quad \frac{B_{0}}{L_{\mathrm{h}}}=5.33 \\
C_{\mathrm{d}} & =1.0, \quad T n_{\mathrm{f}}=30.0
\end{aligned}
$$

また，前に述べたように

$$
\frac{X_{\mathrm{s}}}{L_{\mathrm{h}}}=\sum_{i=0}^{4} a_{i}\left(P_{\mathrm{c}} / P_{\mathrm{b}}\right)^{i}, \quad \frac{Y_{\mathrm{s}}}{L_{\mathrm{h}}}=\sum_{i=0}^{4} b_{i}\left(P_{\mathrm{c}} / P_{\mathrm{b}}\right)^{i}
$$

と近似する . 係数 $a_{i}, b_{i}$ は，すでに述べたように，前報の 方法 ${ }^{2,3)}$ を用いて予め求めたものである.なお，係数 $a_{i}, b_{i}$ を求める段階で必要なパラメータとして次の值を設定して いる。

$$
\frac{L_{\mathrm{s}}}{L_{\mathrm{h}}}=2.2, \quad \frac{L_{\mathrm{v}}}{L_{\mathrm{h}}}=0.5, \quad \frac{w}{P_{\mathrm{b}}}=0.037
$$

ここで, $L_{\mathrm{s}}$ はスカート周長， $w$ はスカートの単位表面積あ たりの重量である . 振動中のスカートの形状を求める際に もこれらの值が必要である.

想定した送風機特性 $\psi(\xi)-\xi$ 曲線を第 3 図に示す。

\section{2 解析結果}

3.2.1 クッション圧力の時間的変化 第 4 図にクッショ ン圧力の時間的変化を示す . 図には 4 つの異なつた振動振 幅 $\Delta H / H_{0}$ に対する変化を示している.ただし， $H_{0}$ は動摇 


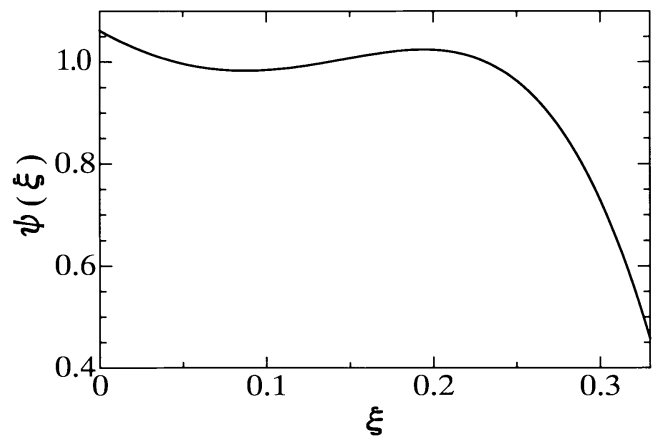

第3 図 送風機特性

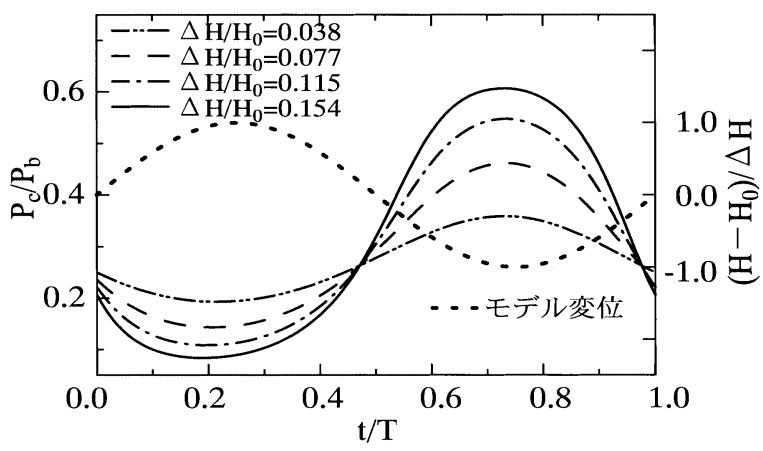

第 4 図 クッション圧力の時間変化

を行う前 (振動変位の中心点) の $H$ の初期值である . 図に はまたモデルの振動変位も示している. 当然ながらモデル が地面に近い位置 ( $H$ が小さい) にあるときほどクッショ ン圧は大きい . しかし , 同じ $H$ の場合でもモデルが上昇 しているか下降しているかによって，クッション圧は異な る.これはモデルの上下方向速度の最大時と最小時て顕著 に現れる.上昇速度が最小 (下向きに最大) $の ~ t / T=0.5$ における圧力は上昇速度が最大時 (上向き) の $t / T=1$ の ときの 1.6 倍に近い . これは $H$ は同じでも圧力はクッショ ン体積が減少しつつあるか増加しつつあるかに依存するか らである. 事実 (4) 式より分かるように, クッション圧は $\mathrm{d} H / \mathrm{d} t$ にも依存している.これに起因して， $H / H_{0}$ を横軸 にとったクッション圧力変化の履歴は第 5 图に示すように ループを描いている．ふらたたび第 4 图を見ると，振幅の増 加に伴い非線形性が表れ，振幅増加の影響が圧力の上昇側 (モデルの上下位置が平均位置より下方にあるとき) で大き く，モデルが最高位置に近い状態では小さい，第 6 図に振 幅と最高圧力との関係を示しているが, 解析範囲ではクッ ション圧は振幅に対してほぼ直線的に増加している。

第 7 図に $T n_{\mathrm{f}}=30$ の場合と静的状態 $(T=\infty)$ におけ る圧力変化を示している.両者はほぼ一致しており，比較 的遅い振動範囲では, クッション圧はほほ静的状態を維持 しながら変化していることが分かる .

3.2.2 スカート 形状の変化 モデルの上下動中のスカー 卜形状の変化を第 8 図に示す . これは振動中の各瞬間にお いて得られた $P_{\mathrm{c}} / P_{\mathrm{b}}$ に対して前報2,3) の方法を用いて求め たものである . 当然ながらスカート变形の状態はクッショ

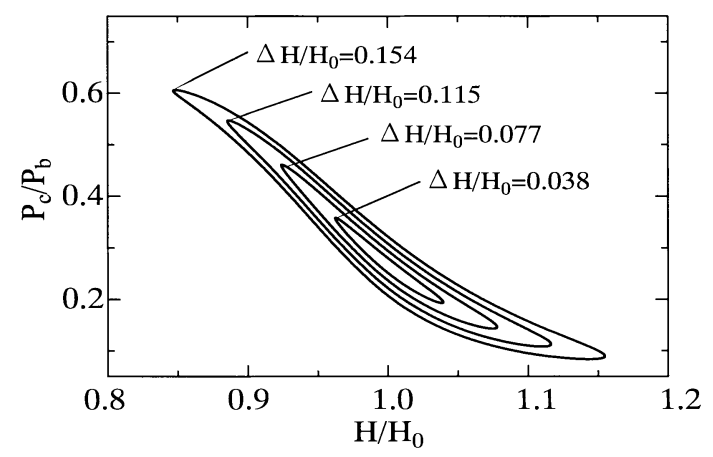

第 5 図 モデル高さの変化に伴うクッション圧力の変化履歴

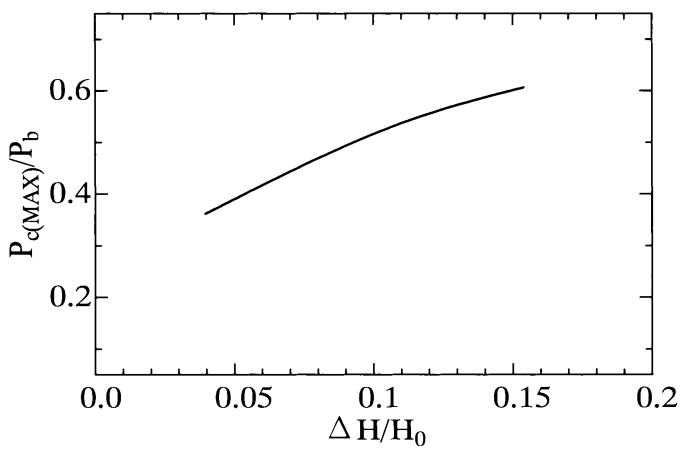

第 6 図＼cjkstart動摇振幅と最大クッション圧力との関係

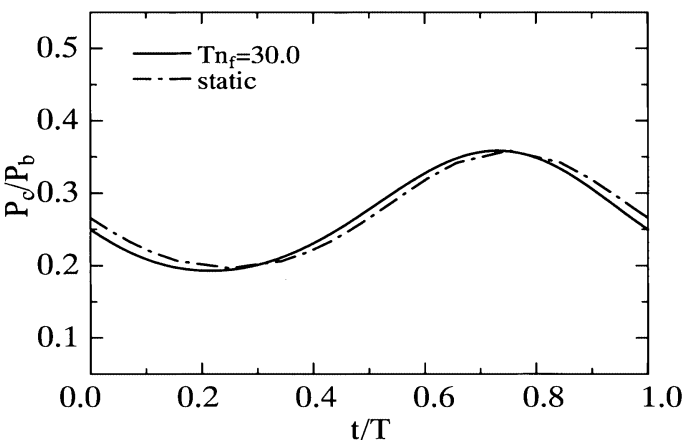

第 7 図 クッション圧力の変化に対する周期の影響 $\left(\Delta H / H_{0}=0.038\right)$

ン圧力の変化に対応している . クッション圧か増えるとス カートは外側に膨らむと同時に扁平になる．扁平になるの はバッグ内圧力に比べてクッション圧が大きくなるためで ある. スカート形状の変化はモデルか地面に一番近い位置 で最も大きい，モデルが地面に近づいたところでは，スカー 卜下端と地面との間隙 (浮揚高) が小さくなりクッション 圧が上昇するが，光れと同時にスカートが外側に移動する ためクッション幅 (クッション面積) か増加する .この二つ が相まって乥こでは，揚力の増加が促進される．したがっ て，スカートを有しない場合に比べるとスカートを装着す ることによって安定性 (復元性) か増加することが期待さ れる.なお，図には振動時の各時刻のモデルの位置と同じ 位置にモデルを保って行った静的状態に対応するスカート 形状も示している．ここでも周期の影響は小さいがモデル が地面に近づいたところでは若干差異が認められる. 

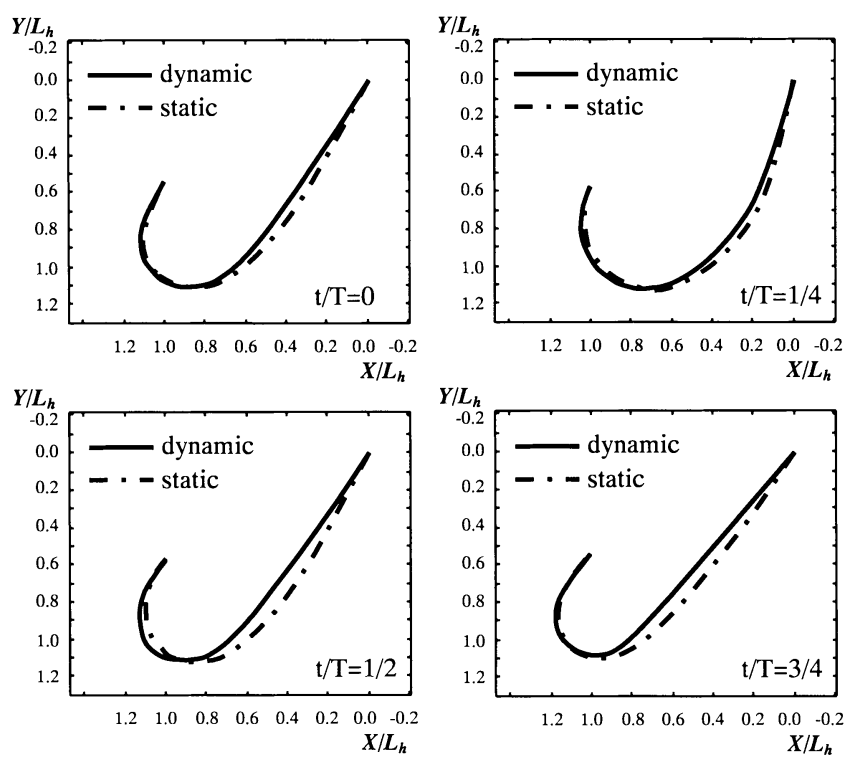

第 8 図 スカートの形状変化 $\left(\Delta H / H_{0}=0.038\right)$

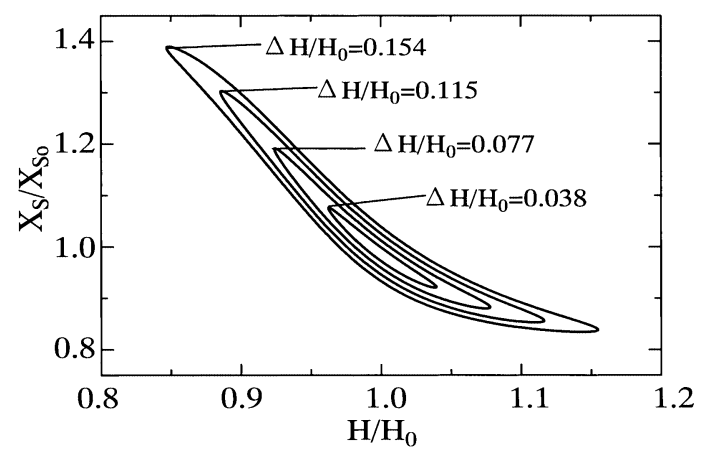

第 9 図 モデル高さの変化に伴うスカート下端位置の水平方向変化 履歴

第 9 图にモデルの上下動に伴うスカート下端の水平位置 $X_{\mathrm{s}} / X_{\mathrm{s} 0}$ の変化をモデルの上下位置 $H / H_{0}$ を横軸にして示 している.ただし， $X_{\mathrm{s} 0}$ は静止状態にあるときの $X_{\mathrm{s}}$ の初 期值である . 上に述べたようにスカートが外側に押し出さ れ，クッション幅が増加している樣子が分かる．また，第 10 図にスカート高さ $Y_{\mathrm{s}} / Y_{\mathrm{s} 0}$ を, 第 11 図にスカート下端と 地面との間隙距離 $h$ を光れぞれ $H / H_{0}$ を横軸にして示して いる.ただし， $Y_{\mathrm{s} 0}$ は静止状態にあるときの $Y_{\mathrm{s}}$ の初期値で ある、これらを見ると，モデルか地面に近づきクッション 圧が上昇するとスカートは外側に押し出されると同時に上 方に押し上げられることが分かる．にもかかわらず，間隙 距離 $h$ は小さくなっている .これはクッション圧の増加に よってスカートが上方に押し上げられる効果がモデルの下 降による間隙の減少を打ち消すほどには大きくないことを 示している。

以上の解析は実用上現れる頻度の高い比較的ゆるやかな 動摇状態を解析の対象としたが，高速域を解析するためには 動的影響とくにスカート慣性の影響を考える必要があろう．

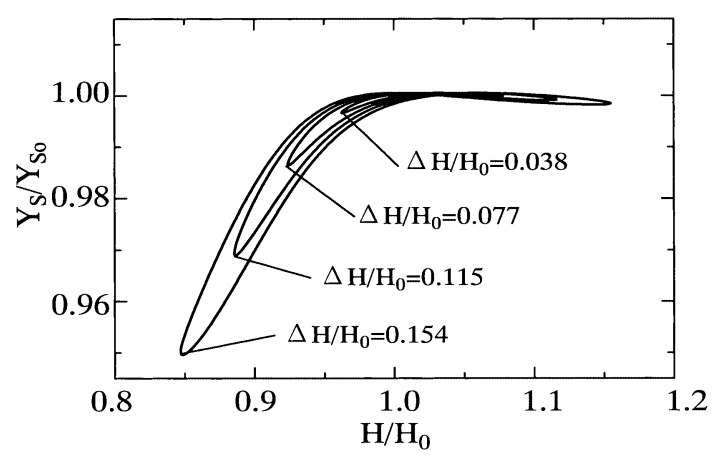

第 10 図 モデル高さの变化に伴うスカート下端位置の垂直方向变化 履歴

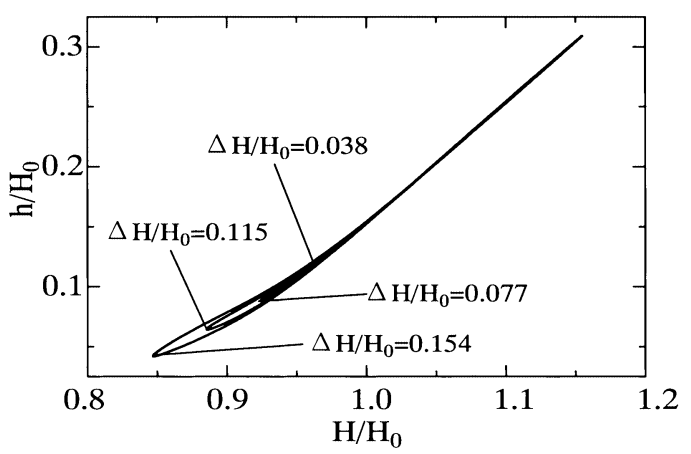

第 11 図 モデル高さの変化に伴う浮揚高の変化履歴

4. あと がき

前報において静止浮揚状態にある ACV バッグスカート の変形特性の解析法を提案し, 良好な結果が得られること を示した . 本報ではこの方法を拡張してモデルの上下動に 伴うスカート变形特性を準静的に解析した . 得られた結果 は次の通りである .

（1）当然ではあるが，モデルが最下点にある付近で圧力 は最も大きい . しかし, 圧力の変化はモデルの位置だけに は依存せずモデルの上下運動速度にも依存し, 上下位置は 同じでもモデルが下降しているときの方が上昇していると きより圧力は大きい .

(2) クッション圧の変化量は, モデル上下動の振幅が大 きいほど当然大きいが, 光の影響は非線形効果により圧力 の上昇側（モデルの上下位置が平均位置より下方にあると き)で大きく現れる .

(3) 実用上現れる上下動が緩やかな範囲では, 圧力の変 化およびスカート形状の変化に及ぼす周期の影響は非常に 小さい.

(4) スカート形状の変化はモデルが地面に近いほど大き く現れる．乥こではクッション圧か増加するためスカート は外側に押し出されると同時に, 上方に押し上げられる しかし，モデルの下降によるスカート下端と地面との間隙 (浮揚高) の減少効果の方がスカート下端の上昇量より大き く光の結果クッション圧は上昇する．

(5) モデルか地面に近づくほどクッション圧か増加して， スカートのバッグ内圧力との差圧が大きくなるためスカー 
卜形状は扁平化する .

(6) モデルが地面に近づいたとき, スカートは変形して 外側へ押し出される.これによって, クッション幅 (面積) が増加し揚力の増加がもたらされる . すなわち安定性が増 加する。

$$
\text { 参 考 文 献 }
$$

1) 松尾日出男, 松尾健輔, 藤原和人 , 廣江哲幸 : ACV におけるバッ
グスカートの形状推定法, 日本航空宇宙学会誌 , 42 (1994), pp. 381-388.

2) 増永雄一，宗 葉子，濱崎左由里：SES のバッグスカートの変 形特性に関する研究, 熊本大学工学部材料開発工学科卒業論文, 1995.

3) 松尾日出男, 松尾健輔, 吉本慎太郎, 千馬浩充 : ACV のバッグ スカートの形状変化に関する実験研究, 日本航空宇宙学会西部支 部講演会講演集，2001, pp. 139-142. 